\title{
Entre a ficção e o posfácio de Jean-Christophe Rufin no romance Rouge Bresil (2001): marcas de um fazer literário comprometido
}

\author{
William Maia \\ Sérgio Cerqueda*
}

\begin{abstract}
Resumo: Este trabalho objetiva refletir sobre a construção do fazer literário no século XXI, a partir do posfácio do romance Rouge Brésil (2001), de Jean-Christophe Rufin. Trata-se de uma obra contemporânea que resgata os relatos de viagem da primeira tentativa de colonização francesa no Brasil, batizada de França Antártica, na Baia de Guanabara, em 1555. As principais reflexões desenvolvidas a partir deste encontro alimentarão as discussões a seguir e serão apoiados nas indagações propostas por Compagnon acerca do papel da literatura nos dias atuais, presentes em sua aula inaugural, no Collège de France (2006); na presença do romance histórico ao longo dos tempos e notadamente seu desdobramento para a obra; Por fim, pretende-se identificar em que medida o romance Rouge Brésil, a partir das linhas gerais contidas em seu posfácio, se insere numa perspectiva literária romanesca francesa, cujo fazer literário apresenta-se em consonância com os ditames do mercado editorial, ao conservar a tendência em ler o ameríndio e, por conseguinte, as coisas do Brasil, através das lentes do estereótipo e do clichê.
\end{abstract}

Palavras-chave: O fazer literário. Jean Christophe Rufin. Rouge Brésil. Estereótipos. Mercado editorial.

\section{Between fiction and postscrip in Jean-Christophe Rufin: Brands and cultural diversity}

\begin{abstract}
This paper aims to reflect on the construction of the literary to the twenty-first century, from the afterword of the postspcript of Rouge Brésil novel (2001) written by Jean-Christophe Rufin. It is a contemporary work that rescues the travel accounts of first attempt at French colonization in Brazil, called Antarctic France, in Guanabara Bay in 1555. The main reflections developed from this meeting will feed the following discussion will be supported the Compagnon of questions about the role of literature in modern, present day in his inaugural lecture at the Collège de France (2006); in the presence of the historical novel over the years and notably its unfolding for the paper aims; Finally, we intend to identify to what extent the of the postscript of Rouge Brésil novel, from the outline contained in his afterword, is part of a French novel literary perspective, whose literary do comes in line with the dictates of the publishing market, while saving the tendency to read the Amerindian and therefore, things in Brazil, through the stereotype and cliché lenses.
\end{abstract}

Keywords: Contemporary literature. Jean Christophe Rufin. Rouge Brésil. Historical romance. Stereotypes

\section{Introdução}

O que se entende por fazer literatura nos dias atuais? O fazer literário deverá estar isento das influências do meio que o cerca? Os autores estariam livres para conceber seus projetos literários tal como imaginaram? Até que ponto o mercado editorial impõe seus ditames sobre a

\footnotetext{
* Mestre em Literatura e Cultura - Universidade Federal da Bahia UFBA (2013). Professor auxiliar da Universidade do Estado da Bahia (UNEB) Campus II Alagoinhas/BA. E-mail: williamlimamaia@gmail.com

* Doutor em Letras e Linguística pela Universidade Federal da Bahia, Brasil (2006). Professor Adjunto da Universidade Federal do Sul da Bahia. E-mail: Cerqueda@uol.com.br
} 
construção do projeto literário de um autor? E o que dizer dos prêmios literários? Estariam eles atrelados a uma lógica de mercado a despeito de seu valor literário? Responder a todos esses questionamentos ou esgotar essa discussão nas linhas a seguir, certamente não é a proposta desse trabalho, entretanto, utilizaremos algumas dessas indagações como premissas na discussão do fazer literário, praticado na atualidade, tomando como origem uma determinada obra e autor, ou melhor, a partir da análise do seu posfácio. Para tanto se pretende contar com a colaboração inicial de Antoine Compagnon, através da sua obra "La Littérature, pour quoi faire?" onde o consagrado professor e teórico francês dos assuntos literários, em sua aula inaugural da cátedra de literatura aborda alguns dos valores intrínsecos da literatura, ao mesmo tempo em que apresenta uma reflexão sobre a permanência da literatura enquanto discurso artístico para o homem do século XXI. Ressalte-se que algumas das principais reflexões desenvolvidas a partir desse encontro alimentarão as discussões a seguir, no que tange a construção do fazer literário do romance Rouge Brésil (2001), desenvolvido por Jean-Christophe Rufin. Com efeito, o que se objetiva denunciar com o auxílio desses teóricos pressupostos é a construção de um projeto literário em consonância aos interesses de uma lógica editorial, cujo objetivo aponta apenas para si mesmo, tanto em relação à manutenção das relações de poder historicamente assentadas entre o colonizador e o colonizado, quanto na reprodução de um projeto literário de cunho reificador sobre a cultura brasileira, pautado em clichés e estereótipos.

Dito isto, o que se pretende associar a partir do resgate de alguns dos questionamentos de Compagnon sobre os poderes da literatura servirá como suporte para analise ou contraponto, em relação a um determinado valor literário de natureza, no mínimo duvidoso, presente ao longo da obra e do seu posfácio do romance Rouge Brésil, aparentemente comprometido com determinadas logicas de mercado, Para tanto, Compagnon norteia sua reflexão, a partir de quatro eixos temáticos.

O primeiro refere-se ao poder que a literatura detém ao "reabilitar o conceito da mimese aristotélica contra Platão que permite reabilitar a poesia em nome da boa vida" Compagnon (2009, p. 30). Trata-se de evocar Aristótelis para chamar a atenção para a literatura que "deleita e instrui". Em relação ao primeiro poder da literatura proposto por Compagnon o autor do romance Rouge Brésil não decepciona totalmente seu publico leitor, visto que organiza de forma cuidadosa a narrativa da sua obra com o explícito objetivo de provocar encantamento diante do 
seu público leitor, ao tentar reproduzir a linguagem e descrever as principais características do século XVI, na busca de legitimar ou reproduzir os pressupostos do romance histórico, sobre o qual se discutirá mais adiante. Já no quesito da literatura que "instrui” Rufin não atinge o mesmo sucesso, sobretudo em relação ao público mais atento. Os sinais emitidos ao leitor, ao longo da narrativa do romance, apesar de apontarem para a rediscussão dos fatos históricos escamoteados entre a França e o Brasil, não sinalizam na direção da ressignificação desses mesmos fatos, e sim, da reificação. Já o segundo poder da literatura convocado por Compagnon, é pertencente ao Século das Luzes, não mais se apresenta como o deleite do período aristotélico, mas como um remédio que concede autonomia ao leitor, liberta-o da sujeição e dos posicionamentos autoritários. Rufin, provavelmente em função dos compromissos mercadológicos assumidos, conforme discussão futura rompe de forma deliberada com o seu leitor, sem cerimonia, desde o inicio da obra, e tenta manipulá-lo até o final, ao escamotear a força, beleza e as tradições da cultura ameríndia reduzidas à barbárie e em pé de guerra contra a civilização francesa, conforme se observa já nas linhas iniciais do romance: o "Imagine só, meu senhor, o que pode sentir um homem que vê ferver à sua frente a água onde vai ser cozido... vocês não comem seus semelhantes, por acaso? Ou é a receita que você contesta, malandro? Rufin (2002, p.11). Quanto ao terceiro do poder da literatura evocado por Compagnon corrigiria os defeitos da linguagem ao recorrer à língua comum, poética ou literária, com o objetivo de "construir um projeto moderno ou modernista ao fazer da literatura uma filosofia, ou a filosofia, isto é, a ultrapassagem dos limites da linguagem ordinária." Compagnon (2009, p. 37). Nesse quesito, Rufin até tenta se preocupar, ao escolher os pressupostos históricos que corroboram na construção do romance Rouge Brésil, a exemplo de Montaigne, a quem dedica a epígrafe do romance. Entretanto, não avança filosoficamente, talvez por estar demasiadamente envolvido pelas observações reducionista de Thevet ou Léry, ao longo da obra, e/ou em função dos compromissos assumidos junto ao mercado editorial. E finalmente, o quarto poder da literatura apontado por Compagnon que não permite o exercício sobre ela mesma, ou sua (in)utilidade. A literatura, dessa maneira, se apresentaria contra qualquer engajamento que "fizeram a escolha radical do impoder, do despoder, ou do fora do poder, como aplicação de qualquer desautorização social ou moral, de menor valor de uso da literatura" Compagnon (2009, p. 41). Rufin parece não ignorar suas responsabilidades, diante desse último poder ao realizar o projeto literário do romance Rouge Brésil. Entretanto, mais uma vez, seus engajamentos editoriais, e por extensão, mercadológicos, 
seus patrocinadores, seus compromissos assumidos diante da academia francesa que o chancelou no ano do lançamento do romance, provavelmente o impedem de transitar livremente.

Compagnon ciente do valor da literatura a despeito de viver inserido em um contexto em que o tempo parece se comprimir face à simultaneidade dos fazeres ou diferentes interesses da vida moderna, reforça o caráter humanizador da literatura, junto ao indivíduo, que desenvolve sua criticidade e, por conseguinte, a possibilidade de atribuir sentidos mais consistentes e relevantes à experiência humana. O que, definitivamente, não parece ser o foco principal do projeto literário desenvolvido no romance de Rufin. Isso porque, em suas palavras, a literatura:

[...] percorre regiões da experiência que outros discursos negligenciam, [...] arruína a consciência limpa e a má-fé, [...] resiste à tolice não violentamente, mas de modo sutil e obstinado [...] visando menos a enunciar verdades que a introduzir em nossas certezas a dúvida, a ambiguidade e a interrogação [...] faz, entretanto, com mais atenção que a imagem móvel e mais eficácia que a anedota policial, pois seu instrumento penetrante é a língua, e ele deixa toda sua liberdade para a experiência imaginária e para a deliberação moral, particularmente na solidão prolongada da leitura [...] continua sendo a melhor introdução à inteligência da imagem (COMPAGNON, 2009, p. 50-55).

A reflexão a seguir, visa enumerar os agentes envolvidos no mercado literário e ao mesmo tempo revelar algumas de suas consequências ou desdobramentos. Por exemplo, a quem interessa os prêmios literários e quais consequências eles engendram de imediato sobre a obra e a sua recepção? A proposta desta discussão como já foi dito anteriormente, não é encontrar respostas a todas essas inquietações levantadas. Contudo, não se pode deixar de atentar para o modus operandi do fazer literário no século XXI, influenciado notadamente por um mercado editorial em busca de um novo segmento a explorar, ou de um antigo a revalorizar. Trata-se aqui dos romances derivados das experiências de viagem, muito em voga nos dias atuais que apresentam narrativas histórico-ficcionais e em geral retratam o encontro de culturas situadas em campos opostos, centro e periferia, apoiadas em representações desfocadas pelas lentes míopes dos estereótipos, a exemplo do romance Rouge Brésil (2001) ${ }^{1}$, de Jean-Christophe Rufin. A peculiaridade que caracteriza a obra de Rufin se assemelha às narrativas de viagens do século XVI, apostando num olhar distanciado com que o autor procura retratar a cultura periférica, notadamente visualizada na representação do ameríndio brasileiro. Aliás, o que faz uma obra

${ }^{1}$ Ano do lançamento do livro. A edição em língua portuguesa intitulada Vermelho Brasil só estaria disponível no ano de 2002. 
obter êxito no mercado editorial a partir de um fazer literário que não desloca, não instiga a alteridade, não ultrapassa os limites da linguagem ordinária, enfim, não ressignifica a temática sobre a qual se propõe a discorrer, apesar de dispor de cerca de quinhentos anos para refletir? Como um romance que se inscreve numa tradição da literatura, que reforça os clichês e os estereótipos sobre os sujeitos, não suscita grandes debates na atualidade, é merecedor de um prêmio literário tão prestigiado, como o Goncourt? O que isso representa, além do imediato aumento das vendas diante do público leitor? Pistas são lançadas na contracapa da edição brasileira por intermédio de comentários elogiosos como "Vermelho Brasil é uma obra prima: deixe-se canibalizar-se por este grande romance" (Gérard de Cortanze, Magazine Littéraire) ou uma "saga à la Alexandre Dumas" (Paris Match) vem corroborar junto à recepção da obra literária nos dias atuais, a partir de uma grande campanha de marketing a seu favor.

Desavisadamente ou não, os leitores consomem a obra Rouge Brésil, talvez por modismo pelo simples fato de estar sendo orientado por um discurso engajado pela noção de centro, provavelmente ditado, a partir dos interesses de um determinado mercado editorial, em busca de novos mercados consumidores. Esses leitores desatentos embarcam numa narrativa impregnada de visões de mundo que reduzem a capacidade crítica do leitor, ao mesmo tempo em que preconizam a estereotipização da cultura periférica. Ao contrário das reflexões sugeridas por Compagnon, em sua aula inaugural, essa literatura de viagem parecer estar cada vez mais a serviço da indústria cultural de massa e produz efeitos na construção do imaginário do público leitor, muitas vezes pouco afeito a critica. Essa intromissão da indústria cultural no fazer literário opera no sentido de fazer com que a literatura seja consumida dentro de uma perspectiva que se pretende ou planeja para o seu consumo. Uma obra interessante para o mercado editorial parece ser, portanto, uma obra chancelada por importantes prêmios literários que lhes atribuem um lustre de valor a ser utilizado pelo próprio mercado, na promoção da obra a despeito da qualidade do fazer literário.

Sem dúvida, o romance Rouge Brésil apresenta atributos relevantes em seu fazer literário ao apontar na direção de denunciar os fatos escamoteados pela História oficial, através da narrativa da expedição colonial francesa, batizada de França Antártica, juntamente com todos os seus desdobramentos, ou ainda, o resgate de relatos históricos de cunho ficcional, que tanto 
contribui para a riqueza do romance, apesar de desfocados pelas lentes do estereótipo e do clichê, não deixam de provocar por si só grande deleite junto ao público leitor.

\section{Rouge Brésil, um romance histórico?}

Presente no gênero romanesco desde os gregos, os temas históricos misturavam heróis imaginários, personagens históricas e determinavam as ações temporais dessas personagens. Contudo, foi durante o romantismo, no início do século XIX, com a publicação da obra Ivanoé (1819), do escritor escocês Walter Scott (1771-1832), que surgiu o romance histórico, mistura de História e ficção, que reconstrói ficcionalmente acontecimentos, costumes e personagens históricos. Ao reconstruir o passado, Walter Scott promoveu a revitalização do gênero literário, recriando relatos que apontassem para outras épocas e outros mundos. Ele organizou dramaticamente os acontecimentos e subdividiu o enredo do romance em episódios convergentes em relação à ação principal. Foi Scott o responsável pelo modelo da estrutura narrativa histórica que seria assimilado por outros escritores estrangeiros, tais como: Alfred de Vigny em Cinq-mars (1826), Victor Hugo em Notre-Dame de Paris (1831), Honoré de Balzac em Les Chouans (1829), Alexandre Dumas em Os Três Mosqueteiros (1844), entre outros. Aliás, sobre o romance histórico, Dumas, em seu tempo, declarou que "notre prétention en faisant du roman historique est non seulement amuser une classe de nos lecteurs, qui sait, mais encore d'instruire une autre qui ne sait pas, et c'est pour celle-là particulièrement que nous écrivons" ${ }^{2}$. Ainda sobre Dumas, Gengembre em seu texto sobre o romance historico (2010) afirma que "le projet dumasien dépasse le seul plaisir du bonheur romanesque. Ainsi s'explique la trop fameuse formule : « violer l'histoire pour lui faire des enfants $»{ }^{3}$. Contudo, foi o filósofo húngaro György Lukács (1885-1971), um dos teóricos que mais contribuiu para elucidar as potencialidades, as peculiaridades da literatura em relação à História e, consequentemente, à própria ação histórica, que afirmou: "o que busquei realizar foi uma investigação da interação entre o espírito histórico e a grande literatura, que retrata a totalidade da História". Lukács (2011, p. 28). O romance histórico, segundo Lukács (2011, p. 32), além de não hierarquizar ou dicotomizar os elementos

${ }_{2}$ Dumas apud Gérard Gengembre. p. 369. <http://www.cairn.info/revue-etudes-2010-10-page-367.htm>, consultado em 21/07/2013.

3 Ibid,. p.370. 
ficcionais e factuais, não representa uma abordagem puramente historiográfica, nem literária, mas precisamente a relação entre essas duas contrapartes, a ficção e a História, através das diversas realidades que denotam um conjunto de características específicas em relação à sua forma e tempo. No início do novo milênio, Gengembre (2010) aponta para o projeto ideológico do romance histórico como a sua característica mais marcante:

Sans doute la caractéristique la plus marcante do roman historique contemporain concerne-t-elle à sa portée ideologique ou l'emprise ideologique exercée à la fois par son auteur et les grands débats de notre époque. [...] mais aujourd'hui, c'est la pensée même du sens de l'Histoire qui se trouve mise en jeu, contestée, voire suspecte. (GENGEMBRE, 2010, p. 373).

Ressalte-se aí que o romance Rouge Brésil, ao apresentar um projeto literário, definido polo seu autor, a partir da representação estereotipada dos elementos do Brasil e pelo papel reificador do ameríndio brasileiro na contemporaneidade, ratifica as discussões suscitadas por Gengembre, acerca dos novos romances históricos e releva indícios preciosos para a discussão:

Utiliser un roman comme un assemblage de documents est parfaitement réducteur et ne permet pas d'en saisir la pertinence, ni d'en apprécier la valeur de miroir de notre temps. Car, en dernière analyse, le roman historique de qualité ne nous parle pas du passé. Il nous parle de nous, aujourd'hui (GENGEMBRE, 2010, p. 377).

Nesse contexto, o romance Rouge Brésil opera através do resgate ficcional de relatos de viagens inscritos na História, mais precisamente no século XVI, não ressignifica nem desloca o romance histórico para novas fronteiras ou novas práticas narrativas, e sim, o reinscreve dentro da tradição literária. E quanto à ficção proposta por Rufin que é um espaço de liberdade, não se pode pensar que seja isenta de compromissos, e menos ainda de engajamentos. Ora, a narrativa ficcional do romance Rouge Brésil possui algum engajamento em relação aos valores culturais dos povos retratados? Certamente, não! Rufin, ao longo da narrativa, apresentar-se-á comprometido com os interesses do público colonizador, das instituições tradicionais que o ratificam. Todavia, antes de prosseguir com a discussão acerca do projeto literário do autor a partir do seu posfácio, convém analisar alguns conceitos acerca dos vocábulos estereótipos e clichés presentes notadamente no fazer literário da obra em discussão. 


\section{O estereótipo e o clichê: são inerentes no fazer literário contemporâneo?}

O aparecimento do estereótipo e do clichê nos romances histórico-ficcionais de viagem, ou simplesmente nos romances de viagem, em grande medida resultam da construção de fazer literário do século XXI, que objetiva criar narrativas dinâmicas, fluídas e, muitas vezes superficiais, apoiadas em um olhar quase sempre apressado em relação aos fatos observados. $\mathrm{O}$ que de alguma forma, sinaliza os novos tempos em que o poder do mercado editorial decide o sucesso comercial de determinadas obras, muitas vezes a despeito de sua qualidade literária. Nessa perspectiva, as representações resultantes dos interesses do mercado editorial parecem sobrepor à ressignificação do novo, do periférico. A omissão decorrente do processo do não reconhecimento da alteridade não poderia resultar em outra coisa senão a formação de uma narrativa repleta de conceitos "pré-estabelecidos", ou estereotipados. Aliás, sobre esses conceitos convém observar atentamente a descrição acerca da sua etimologia e assim perceber o tamanho do estrago, do ponto de vista literário, quando essas construções se impõem dentro de uma narrativa, a exemplo do que se observa no romance Rouge Brésil. O termo estereótipo é formado pela justaposição de duas palavras de origem grega: stereos, que significa rígido, sólido e tipo, que significa traço um "traço fixo, inalterável" Pereira (2002, p. 43). Para a tipografia, o termo é utilizado para designar a placa metálica de caracteres fixos a partir da qual se produzia material impresso em série - este processo era denominado "clichagem" ou "estereotipia" no início do século XIX. No dicionário de Paul Robert (1990, p. 1863), o conceito do vocábulo estereótipo apresenta-se veiculado à literatura, a partir do século XX e é descrito como "une opinion toute faite, clichê" ${ }^{4}$. Já a definição do vocábulo clichê, descrito pela mesma fonte, se dá a partir de um contexto figurativo e pejorativo, no ano de 1869. E expressa "une idée ou expression trop souvent utilisée. Banalité lieu commun." ${ }^{5}$ Robert (1990, p. 325). Por sua vez, o dicionário Gradus Les procédés littéraires de Dupriez (1984, p. 117-118) apresenta o termo clichê definido como "idée ou expression trop souvent utilisée...banalité. lieu commun [...] défaut du style, lorsqu'il est consciente s'emploie pour connoter l'absence de sincérité et la prétention." 6

4 Uma opinião construída, clichê.

${ }_{5}$ Ideia ou expressão frequentemente utilizada. Banalidade, lugar comum.

${ }_{6}$ Ideia ou expressão frequentemente utilizada, lugar comum. É um defeito de estilo quando utilizado de forma consciente para conotar a ausência de sinceridade ou pretensão. 
Na linguagem corrente, a concepção do estereótipo aparece atrelada a termos como clichê e lugar comum para designar uma simples reprodução ou uma falta de originalidade ocorrida no enunciado. Por isso, a utilização dessas noções é vista, na maioria das vezes, de forma negativa ou pelo menos "não positiva". Amossy na obra Imagens de Si no Discurso: a construção do ethos, (2011), contribui de forma elucidativa sobre o conceito de estereótipo, a partir da perspectiva prática do termo "estereotipagem":

A operação que consiste em pensar o real por meio de uma representação cultural preexistente, um esquema coletivo cristalizado. Assim a comunidade avalia e percebe o individuo segundo um modelo pré-construído da categoria por ela difundida e no interior da qual ela o classifica. (AMOSSY, 2011, p. 125126).

Em Pereira (2002), o estereótipo atua na compreensão humana a fim de facilitar o processo de diferenciação, generalização e esquematização voltadas para que o indivíduo consiga absorver as inúmeras informações que recebe diariamente, ao mesmo tempo em que utiliza os processos cognitivos para agregar, simplificar e categorizar o mundo e acentuar as características que representam conceitos, grupos ou práticas diversas a partir de ideias relacionadas socialmente com o grupo que as criou ou sustenta.

Esse breve histórico dos termos estereótipo e clichê revela de alguma maneira o julgamento do valor atribuído sobre esses vocábulos, outrora atrelado às identificações préfixadas, reservados para designar uma forma técnica de reprodução em massa de textos impressos, estão presentes no fazer literário, do inicio do novo milênio, notadamente, no romance Rouge Brésil que nos interessa discutir. Somem-se a esses conceitos os pressupostos históricos escamoteados pela França, os interesses do mercado editorial, e a consequente reificação dos valores culturais do ameríndio brasileiro no romance e teremos a tessitura da obra de Rufin. Mas, daí realizar a reconstrução ou ressignificação desses mesmos fatos, segundo sugere o autor no posfácio, Ah! Isso é outra estória...

\section{Rouge Brésil em seu posfácio}


Ao escrever o romance Rouge Brésil, Rufin pretende como ele mesmo indica vivificar o encontro entre as culturas francesa e ameríndia do século XVI. Contudo, após uma leitura mais atenta do posfácio do romance, observa-se construção o projeto literário da obra estruturado, a partir de três momentos distintos. O primeiro, quando se depara com os fatos históricos, na ocasião de uma visita à cidade do Rio de Janeiro; o segundo, quando escolhe suas fontes ou teóricos com quem pretende dialogar, e o terceiro, quando discute a tensão entre a ficção criada e os pressupostos históricos que cercaram a expedição francesa em solo brasileiro. De passagem pela cidade do Rio de Janeiro, Rufin explica como pretende se servir dos fatos "esquecidos" pelas Histórias, tanto do Brasil como da França na formação da sua obra, ao afirmar que:

[...] O mais surpreendente nesta História é que ela seja verdadeira. Não que pareça inverossímil: o Renascimento é rico em aventuras mais extraordinárias ainda. O que constitui sua estranheza é o esquecimento quase total em que caiu este episódio da História da França. Por que tais acontecimentos não deixaram praticamente nenhum vestígio na memoria coletiva? [...] A Louisiana, as colônias de São Lourenço, a Indochina, Pondichéry soam como lugares de presença francesa; já o Brasil não evoca nada disso, e o nome de Villegagnon caiu num esquecimento total. (RUFIN, 2002, p. 402).

Dessa forma, o autor em visita a baía de Guanabara Rufin mostra-se sensível à evocação poética que aquele encontro havia provocado e decide chamar atenção do seu leitor para o fato de que a sua obra ficcional é uma reconstrução dos acontecimentos históricos:

[...] A evocação poética desses primeiros encontros me atraiu irresistivelmente. Reconheci aí o tema que é minha maior obsessão: o do primeiro encontro entre civilizações diferentes, o instante da descoberta que contém em germe todas as paixões e todos mal-entendidos futuros. Esse momento efêmero e único encerra uma emoção particular; ainda que diga respeito a sociedades, tem parentesco com o impulso amoroso que pode se apoderar de dois seres quando eles se veem pela primeira vez. (RUFIN, 2002 p. 402).

Com efeito, o encontro do autor com a História, in loco, bem como a perspectiva de escrever um romance, parecer ter sido o momento mais encantador do projeto da obra, pois, passados esse breve período de extrema sensibilidade Rufin, necessitaria, em um segundo momento, escolher as fontes com as quais pretendia dialogar. Observa-se que o escritor, ao selecionar os teóricos para discutir a alteridade resultante desse "encontro de civilizações", com 
culturas tão distintas, que viria a se materializar na obra, privilegiou a cultura europeia e colonizadora, ao convocar basicamente cânones franceses, tais como: Thevet, Léry, Montaigne e tantos outros. A maioria desses relatos que lhe serviram de sustentação encontra-se presente nas discussões centrais do romance estão ligados por uma característica comum, notadamente marcada pela intransigência.

No momento em que uma forma de se fazer literatura no século XXI, insiste em produzir narrativas que se apresentam impregnadas pelos discursos do século XVI, sem os questionar, e cujo único interesse parece ser a manutenção das relações de poder assentadas historicamente, do civilizatório sobre a barbárie, é necessário destacar o fazer literário do romance enquanto um exemplo de propagação de uma ideologia dominadora:

[...] Por que não fica aqui? - Perguntou Pay-Lo. - Os índios precisam de um homem como o senhor, para lhes ensinar a lutar como os europeus. Chegará um dia em que eles não terão mais que se defender de bandidos, mais sim de exércitos. (RUFIN, 2002, p. 346).

Apesar de o romance obedecer aos pressupostos de um romance histórico, Rufin não questiona a tradição histórica que ele diz pretender combater. A rigor, ele a reforça, apesar do posfácio da obra traduzir a intenção de recuperar e de dar uma nova perspectiva a essa tradição esquecida, a partir de expedição francesa ao Rio de janeiro:

[...] Uma tal abundância de trabalhos consagrados a esses tema produziu em mim um duplo efeito de frustração e paralisia. Frustração, porque, malgrado, sua qualidade, nenhuma dessas abordagens correspondia à representação imaginária que eu fazia desses acontecimentos. Nenhuma satisfazia a vontade que eu tinha de contar essa História a meu modo, em ressonância com minha própria vida, minhas ideias, meus sonhos e, sobretudo fazendo as ligações necessárias com a época presente. (RUFIN, 2002, p. 405).

As representações presentes no romance decididamente, não deslocam ou atribuem um novo sentido aos fatos. Na prática, o romance esvazia as potencialidades de novas interpretações dos fatos históricos escamoteadas nas relações entre a França e o Brasil, ao mesmo em que produz um efeito contrário em relação ao que Rufin quer acreditar em seu posfácio. Como consequência desta realidade o fazer literário apresentado no romance, condena a reificar a 
imagem do encontro entre os nativos brasileiros e o povo francês, quando na realidade, poderia perfeitamente abalar todos os relatos historicamente constituídos através da adoção de novas focalizações narrativas. Mas, certamente, essa não era a sua intenção. O terceiro e último ponto nevrálgico discutido por Rufin no seu posfácio, refere-se à tensão entre a ficção e a História. Ao sinalizar o desejo de dar uma nova perspectiva à tradição, negada pelos fatos históricos, por mais que se compreenda que Rufin, como um cidadão europeu, tivesse dificuldades em lidar com a construção da voz do indígena, por exemplo, ele poderia ter tentado fazer esse exercício, isto é, o de dar voz direta ao habitante natural brasileiro, apesar de todos os problemas que tal escolha pudesse engendrar na construção da narrativa.

Na medida em que a voz do ameríndio permanece ausente da obra, ou melhor, se revela filtrada pelo narrador, numa perspectiva onipotente e onisciente, o romance Rouge Brésil, apesar de toda a beleza que a obra possa evocar, não atinge os objetivos propostos no seu posfácio, compromete a lisura do seu fazer literário, ao mesmo tempo em que se reduz a um romance de metrô ${ }^{7}$, escrito com o objetivo de entreter o imaginário coletivo do público leitor alvo, notadamente o francês metropolitano. Ressalta-se que o romance, ao receber o prêmio maior da academia francesa, se investe da chancela de autoridade junto do meio literário, como mais um representante das instituições preservadoras da tradição e produz, junto aos leitores mais atentos, certa desconfiança acerca do caráter tradicional e reificador da obra. O romance permanece fiel à tradição romanesca francesa em crise, ao preterir dialogar com a alteridade, e preferir a voz que não é voz, a representação que não é representação, e sim, simulacro.

\section{Considerações finais}

A análise do fazer literário do posfácio do romance Rouge Brésil, proposto por Rufin, revela-se essencialmente reificadora. As representações do indígena que emergem no romance aparecem associadas às palavras: barbárie, selvagem, inferior ou escrava. Ao dialogar com as

\footnotetext{
${ }^{7}$ Tipo de romance preferencialmente escolhido por apresentar leitura rápida, fácil e fluida, durante os deslocamentos diários em transportes urbanos, nas grandes cidades. Romance que estabelece facilmente uma conexão com o seu público, e com este apenas, ao representar seus anseios, seu imaginário e dirimir rapidamente suas dúvidas, através de clichês, ou soluções prontas. Romance repleto de sentenças estereotipadas, que reduzem ou simplificam as
} 
diferentes narrativas ou relatos de acordo com as fontes apresentadas pelo próprio autor no posfácio do romance, certamente, é com o Thevet, representante maior da tradição francesa, que o romance parece se identificar em maior ou menor intensidade, ao absorver o essencial das suas ideias e representações negativas acerca do ameríndio brasileiro. Com Léry, demostra corroborar em alguns poucos momentos quando identifica beleza ou virtude na cultura indígena, ou exercita a tolerância. Montaigne talvez lhe tenha servido de inspiração, segundo lhe convém acreditar, pois é para o autor que Rufin dedica a epígrafe do romance: "Tive por muito tempo comigo um homem que permanecera dez a doze anos neste outro mundo que foi descoberto em nosso século, no local em que Villegagnon aportou ao qual chamou de França Antártica" (Ensaios I, XXXI). Contudo, o romance ignora a representação positiva do indígena brasileiro, que aos poucos se tornaria realidade na obra de Montaigne, sobretudo, no momento em que ele reconhece na sociedade indígena brasileira, os verdadeiros traços desses habitantes da floresta, que julga encarnar a pureza, a lealdade e a coragem. O que prevalece no conjunto da obra são representações dos povos indígenas pautadas a partir de valores inerentes à cultura europeia, particularmente, a francesa, de forma a não relativizar as diferenças culturais. Nesse sentido, o fazer literário proposto por Rufin, ao prender-se a noções etnocêntricas, dá indícios de não aceitar a alteridade, ignorando, por consequência, a máxima de Montaigne, quando este afirma: "ao considerar que nada há de bárbaro e selvagem naquela nação, senão que cada qual chama de bárbaro o que não pratica em sua terra”. Montaigne (1996, p. 195). A rigor, a tentativa de diálogo de Rufin com o autor dos Ensaios tem lugar marcado no romance, não vai além da epigrafe, na medida em que se percebe em sua narrativa, a busca incessante pelos valores europeus na sociedade indígena descrita.

$\mathrm{Na}$ diversidade de escritas, entre o posfácio e as histórias, Rufin cria sua obra baseada na historiografia francesa, mas renuncia à oportunidade de rediscutir ou reinventar seu fazer literário ao permite significar a alteridade entre as culturas europeia e indígena brasileira e, portanto, ressignificar a História. De maneira que ficção produzida por Rufin se apresenta como "a verdadeira aliada do passado, comprometida em legitimar o discurso, ou as práticas vencedoras" Loriga (2012). Com efeito, o escritor francês evita rediscutir conceitos e pré-conceitos culturais por insistir em reproduzir, apenas, o gosto francês pelo exotismo americano e, particularmente, 
pela representação do indígena brasileiro. Como consequência, a narrativa da obra Rouge Brésil ignora a possibilidade de rediscutir a representação do nativo brasileiro sob o viés da cultura moderna, uma vez que constrói a sua estrutura com base em um olhar retroativo aos relatos franceses do século XVI, onde a construção do ameríndio foi lida através de imagens e clichês afeitos às demandas do público francês, baseado na premissa de que:

Parte do mesmo diagnóstico de que os franceses conhecem mal este país, reduzindo-o a estereótipos que se organizam em torno de imagens eufóricas. Para superar a superficialidade do olhar exótico, projeta uma imagem ambivalente do Brasil, fazendo coabitar marcas positivas e negativas. Não escapam, no entanto, de visão simplista e dicotômica em maior ou menor grau. (LISBOA; MOREIRA; BERND, 2009, p. 52).

Outra estratégia revelada por esse fazer literário míope em maior ou menor grau referese às explicações didáticas presentes na obra acerca dos aspectos culturais e históricos da realidade brasileira cujo objetivo é "compensar a superficialidade do olhar ao qual faz alusão, quando traduz, explica ou descreve compulsivamente os dados estrangeiros" Lisboa; Moreira;

Bernd (2009, p. 52). Observa-se ainda que o romance, ao se libertar da compulsão etnocêntrica e civilizadora que o persegue ao longo da narrativa, no que tange à representação do ameríndio e da sua cultura, se investe de uma "consciência etino-antropológica, a fim de desenvolver um processo de compreensão e de interpretação dos dados materiais da cultura brasileira minuciosamente descrita nos textos romanescos". Lisboa; Moreira; Bernd (2009, p. 52). Nesse instante, percebe-se o esforço do autor no sentido de "realizar o diálogo e até mesmo ultrapassar os estereótipos. Entretanto, as boas intenções não garantem o sucesso da realização literária".

Lisboa; Moreira; Bernd (2009, p. 52).

O romance Rouge Brésil está inserido assim numa tendência literária atual que explora, de alguma forma, as poéticas do ameríndio brasileiro, na construção de uma narrativa com a perspectiva de entreter um determinado público que, segundo Rivas, corresponde à "visão de um Brasil Outro correspondendo à elaboração mítica de um Brasil como complemento da França, como contrapartida da incompletude francesa". Rivas (2005, p. 75). Enfim, explorar as relações identidade/alteridade e respeitar a opacidade do outro, sem cair na tentação da clicherização das diferenças culturais, continua sendo uma tarefa difícil, segundo adverte Euridice Figueredo, no seu estudo sobre a representação do Brasil na literatura quebequense contemporânea: 
Torna-se necessário ultrapassar os topoi, as imagens onipresentes na representação do Outro que o reificam numa essência fixa. A adesão a uma poética da alteridade possibilita que a viagem que induz a uma 'arqueologia' de culturas e de povos se realize ao nível da linguagem. Essa escolha tem a ver com o projeto literário e o talento de cada autor para assumir o caráter visionário da literatura, criando uma alternativa de sentido: uma literatura que seja menos o espetáculo do mundo, no dizer de Daniel Pageaux, retomando Sartre, do que a força das palavras. (FIGUEREDO, 2000, p. 563-575).

O romance "Rouge Brésil”, escrito por Rufin em 2001, ainda sob o impacto, talvez, dos festejos dos 500 anos do encontro entre os povos americanos e europeus, resultou, primeiramente, de um trabalho de pesquisa acerca da historiografia escamoteada entre as literaturas da França e do Brasil. O que, aliás, Rufin resgata com sucesso, apesar de privar os leitores de uma rediscussão sobre a representação do ameríndio brasileiro à luz da atualidade. Ao fazê-lo, porém, escolhe dialogar com as narrativas e imagens da tradição francesa apoiadas em representações reificadas, exóticas e repletas de clichês ou estereótipos, situadas em algum lugar entre os séculos XV e os dias atuais. Apesar de dispor de aproximadamente cinco séculos de produção de relatos de viagens, narrativas, textos literários ou filosóficos de toda natureza, assim como diversas reflexões sobre o tema, Rufin prefere dialogar essencialmente com Thevet e Léry, divagar com as ideais de Montaigne, receber títulos, se consagrar junto ao mercado editorial e, finalmente, realizar o que tanto se esperava da obra, ou seja... mesmice!

\section{Referências}

AMOSSY, Ruth. (Org.). Imagens de Si no Discurso: a construção do ethos. Ruth Amossy (org.). 2. ed. São Paulo: Contexto, 2011..

ARISTÓTELIS. Arte Retórica e Arte Poética. 17. ed. Tradução de Antônio Pinto de Carvalho. Rio de Janeiro: Ediouro, 2005.

ARON, Paul; VIALA, Alain; VAILLANT, Alain Roman. Le dictionnaire du littéraire. 2. ed. Paris: PUF, 2010.

COMPAGNON, Antoine. Literatura para quê? Tradução de Laura Taddei Brandini. Belo Horizonte: Editora UFMG, 2009.

CUNHA, Eneida Leal. Estampas do Imaginário: literatura, História e identidade cultural. Belo Horizonte: Editora UFMG, 2006. 
DUPRIEZ, Bernard. Gradus Les Procédés Littéraires. Dictionnaire. Paris: Editions 10/18, Département d'Univers Poche, 1984.

FIGUEREDO, Euridice. Representações de Etnicidade perspectivas interamericanas de literatura e cultura. Rio de janeiro: 7Letras, 2010.

FIGUEREDO, Euridice. Representations du Brésil dans la Literature Québécoise Contemporaine, Voix et Images. vol. 25, n 3, (75), Montréal: Université du Quebec, 2000.

GENGEMBRE Gérard. Le Roman Historique: mensonge historique ou vérité romanesque? Études, 2010/10 Tome 413. Disponível em <http://www.cairn.info/revue-etudes-2010-10-page367.htm>. Acesso em 21 jul. 2013.

LÉRY, Jean de. Viagem à Terra do Brasil. Tradução e notas de Sérgio Millet; bibliografia Paul Gaffarel; Colóquio na literatura brasílica e notas tupinológicas Plínio Ayrosa. Belo Horizonte: Ed Itatiaia, 2007.

LESTRINGANT, Frank. $O$ Canibal: grandeza e decadência. Tradução de Mary Murray Del Priore. Brasília: editora Universidade de Brasília, 1997.

LORIGA, Sabina. La Mémoire entre l'Histoire et la Littérature. (Conferência) Paris: L'école des hautes études en sciences sociales. 17-20 Jan. 2012. Documento Sonoro.

LORIGA, Sabina. O Pequeno X: da biografia à História. Tradução de Fernando Scheibe. Belo Horizonte: Autêntica Editora, 2011.

LUKÁCS, György. Ensaios sobre literatura. Tradução de Leandro Konder. 2. ed. Rio de Janeiro: Civilização Brasileira, 1968.

LUKÁCS, György. O Romance Histórico. Tradução de Rubens Enderle. São Paulo: Boitempo, 2011.

MELO, Ana Maria Lisboa de; MOREIRA, Maria Eunice; BERND, Zilá (orgs.). Pensamento Francês e Cultura Brasileira. Porto Alegre: EDIPUCRS, 2009.

MONTAIGNE, Michel Eyquem. Ensaios. (Os pensadores). Vol. I. Tradução de Sérgio Millet. São Paulo: Editora Nova Cultural, 1996.

MONTAIGNE, Michel Eyquem. Ensaios. (Os pensadores). Vol. II. Tradução de Sérgio Millet. São Paulo: Editora Nova Cultural, 1996.

PEREIRA, M. E. Psicologia Social dos Estereótipos. São Paulo: E.P.U., 2002.

PEREIRA, Marcos Emanuel, LIMA, Marcus Eugênio Oliveira. Estereótipos, preconceitos e discriminação. (Orgs.). Revisão de textos dos autores; capa editoração Joe Lopes. Salvador: EDUFBA, 2004. 
RIVAS, Pierre. O Brasil no Imaginário Francês: tentações ideológicas e recorrências míticas e o mito brasileiro na França. Diálogos interculturais. São Paulo: Hucitec, 2005.

RUFIN, Jean-Christophe. Rouge Brésil. Paris: Gallimard, 2001.

RUFIN, Jean-Christophe. Vermelho Brasil: o romance da conquista do Brasil pelos franceses. Tradução de Adalgisa Campos da Silva. Rio de Janeiro: Objetiva, 2002.

ROBERT, Paul. Le Petit Robert 1. Paris: Le Robert, 1990.

SCOTT, Walter. Ivanoé. Tradução de Brenno Silveira. São Paulo: Livraria Martins Editora. 1972.

THEVET, André. A Cosmografia Universal de André Thevet. Col. Franceses no Brasil V. $21^{\mathrm{a}}$ Ed. Rio de Janeiro: Batel, 2009.

THEVET, André. As Singularidades da França Antártica. Tradução de Eugênio Amado. Belo Horizonte: Ed. Itatiaia; São Paulo: Ed. Da Universidade de São Paulo, 1978.

VIALA, Alain. Le dictionnaire du littéraire. 2. ed. Paris: PUF, 2010.

Recebido: 10.07.2015

Aceito: 20.08.2015 